\title{
Nonactin hinders intracellular glycosylation in virus-infected baby hamster kidney cells
}

\author{
JIN-MAN LEE ${ }^{1}$, JONG-GUK KIM ${ }^{2}$, TAE-HO KIM ${ }^{4}$, DO SEUNG LEE ${ }^{5}$, JAE HOON KIM ${ }^{5}$, \\ SOMI K. CHO ${ }^{5}$, KEY ZUNG RIU ${ }^{5}$, DONG-SUN LEE ${ }^{*}$ and SANG-HAN LEE ${ }^{3 *}$ \\ ${ }^{1}$ Department of Food and Biotechnology, Hoseo University, Asan 336-795; ${ }^{2}$ School of Bioscience and Biotechnology, \\ and ${ }^{3}$ Food and Bio-Industry Research Institute, Kyungpook National University, Daegu 702-701; \\ ${ }^{4}$ Skeletal Diseases Genome Research Center, Kyungpook National University Hospital, Daegu 700-412; \\ ${ }^{5}$ Faculty of Biotechnology, Jeju National University, Jeju 690-756, Korea
}

Received August 26, 2009; Accepted September 28, 2009

DOI: $10.3892 / \mathrm{mmr} 00000227$

\begin{abstract}
Potent antiviral agents hinder virus-infected cell machinery, leading to rescue from viral damage. In this study, we aimed to identify selective intracellular glycosylation inhibitor(s) that do not suppress glycoprotein synthesis. Our results showed that nonactin is a potent inhibitor of intracellular glycosylation. First, we examined the effects of nonactin on syncytium formation and cytopathic activity in virus-infected baby hamster kidney cells. Nonactin effectively inhibited syncytium formation in a concentration-dependent manner, and infectious virus production was markedly reduced. However, glycoprotein synthesis was not affected. In the presence of $5 \mu \mathrm{g} / \mathrm{ml}$ nonactin, we observed the intracellular accumulation of vesicular stomatitis virus- $G$ protein as well as syncytium formation, but no significant effects on Newcastle disease virus-hemagglutinin-neuramidase glycoprotein synthesis. Our results collectively indicate that nonactin potentially inhibits glycosylation by acting as a suppressor of intracellular glycosylation trafficking.
\end{abstract}

Correspondence to: Professor Sang-Han Lee, Department of Food Science and Biotechnology, Kyungpook National University, Daegu 702-701, Korea

E-mail: sang@knu.ac.kr

Professor Dong-Sun Lee, Faculty of Biotechnology, Jeju National University, Jeju 690-756, Korea

E-mail: dongsunlee@jejunu.ac.kr

${ }^{*}$ Contributed equally

Abbreviations: $\mathrm{BFA}$, brefeldin $\mathrm{A} ; \mathrm{IC}_{50}, 50 \%$ inhibitory concentration; HIV, human immunodeficiency virus; NDV-HN, hemagglutininneuramidase; HAU, hemagglutination units; HAD, hemadsorption; CPU, cytopathic units; SF, syncytium formation; CPE, cytopathic effects; BHK, baby hamster kidney; NDV, Newcastle disease virus; VSV, vesicular stomatitis virus; PFU, plaque forming units

Key words: nonactin, intracellular glycosylation, inhibitor, antiviral, trafficking

\section{Introduction}

Glycoproteins play a key role in various physiological responses in mammalian cells. These proteins are synthesized and secreted in cell membranes via the Golgi complex $(1,2)$, and transported between membrane-bound organelles by repeated cycles of budding and the fusion of secretory vesicles (3-5). A number of biochemical and genetic approaches have been used to identify numerous components of the machinery that mediates transport (6). Previously, an in vitro intra-Golgi transport assay was used to purify a cytosolic transport factor (7-8). Brefeldin A (BFA) blocks the cell surface expression of viral glycoproteins (9). The use of chemicals affecting intracellular trafficking may in future serve as an important tool for examining the molecular mechanisms of the glycoprotein secretory pathways, with the aim of determining the underlying mechanisms of viral infections, cancer and other degenerative diseases (10-11).

To date, the mechanisms of this type of glycoprotein processing and the flow of cellular transport have only been partially determined, and the overall mechanistic machinery remains to be established. In the course of screening for a selective inhibitor of cellular transport trafficking of vesicular stomatitis virus (VSV) G-protein, we isolated purified nonactin from the culture filtrate of Streptomyces viridochromogenes JM-4151 (12). In the current study, we examined whether nonactin exerts inhibitory effects on intracellular glycosylation in cultured mammalian cells, and discuss its potential use in anti-viral therapy.

\section{Materials and methods}

Cells, viruses and reagents. Baby hamster kidney (BHK) cells were grown in Eagle's minimum essential medium (Gibco, Carlsbad, CA, USA) supplemented with $10 \%$ calf serum (Gibco) at $37^{\circ} \mathrm{C}$ in a humidified $\mathrm{CO}_{2}$ incubator (5\% $\mathrm{CO}_{2}-95 \%$ air). Newcastle disease virus (NDV; Miyadera strain) and VSV (New Jersey serotype) were obtained from the National Institute of Health (Korea), and were propagated on BHK cells. The resulting virus stocks were titrated using 
an assay of plaque forming units (PFU) on monolayers of BHK cells. Stocks of VSV were stored at $-80^{\circ} \mathrm{C}$ (Nihon Freezer, Tokyo, Japan). All other chemicals were purchased from Sigma Chemical Co. (St. Louis, MO, USA). Nonactin (Fig. 1) was isolated and characterized from the culture broth of Streptomyces viridochromogenes JM-4151 using various analytical procedures (12).

Antimicrobial Assay. The antimicrobial activity of nonactin was determined on Bacillus subtilis KCTC3069 ( $\mathrm{rec}^{-}$) and B. subtilis ATCC6633 (rec $\left.{ }^{+}\right)$strains with an agar diffusion method (13). The minimum inhibitory concentration (MIC) of nonactin against test microorganisms was determined with the conventional 2-fold serial agar dilution method using the Mueller Hinton agar (14).

Measurement of superoxide radicals. Generation of superoxide radicals was determined using the nitroblue tetrazolium (NBT) assay (15,16). Bacillus subtilis KCTC3069 (rec-) was homogenized in $0.1 \mathrm{M}$ potassium phosphate buffer ( $\mathrm{pH} 7.0$ ) containing $0.15 \mathrm{M}$ potassium chloride and $1 \mathrm{mM}$ EDTA, and centrifuged at 5,000 rpm for $20 \mathrm{~min}$. The supernatant was used as the cell lysate. Reaction mixtures $(1 \mathrm{ml})$ containing cell lysate $(0.8 \mathrm{mg}$ protein $/ \mathrm{ml}), 0.05 \%$ NBT (Sigma Chemical Co.) and various concentrations of drugs were incubated in the presence or absence of superoxide dismutase (SOD; Sigma Chemical Co.) from bovine erythrocytes $(130 \mu \mathrm{g} / \mathrm{ml})$ at $37^{\circ} \mathrm{C}$ for $30 \mathrm{~min}$, followed by the addition of $2 \mathrm{ml}$ of $1 \mathrm{~N} \mathrm{HCl}$ to the solution, and centrifuged at 5,000 rpm for $20 \mathrm{~min}$. The residue was washed with $1 \mathrm{~N} \mathrm{HCl}$ and dissolved in $1 \mathrm{ml}$ of hot pyridine (Sigma Chemical Co.). Absorbance of the supernatant was measured at $515 \mathrm{~nm}$.

Syncytium formation and cytopathic effects. Monolayer cultures of BHK cells in 96-well microtiter plates were infected with NDV or VSV, and the syncytium formation (SF) and cytopathic effects (CPE) in NDV- and VSV-infected cells, respectively, were observed under an optical microscope (17). Infectious virus production was quantified and expressed as cytopathic units (CPU). The medium fraction of VSV-infected BHK cells in each well was serially diluted 2-fold and added to BHK cells in 96-well microtiter plates. CPU was expressed as the maximum number of dilutions tolerated to cause CPE.

Cell growth. BHK cells were seeded in each well of 96-well plates, treated with 2-fold serially diluted concentrations of compounds and incubated at $37^{\circ} \mathrm{C}$ in a $\mathrm{CO}_{2}$ incubator. Cell growth was determined with a colorimetric method using 2-(4-iodophenyl)-3-(4-nitrophenyl)-5-(2,4-disulfophenyl)-2H-tetrazolium monosodium salt (Sigma Chemical Co.) (18) according to the manufacturer's manual. Growth was determined daily for 3 days and duplicate samples were used for each determination.

Hemagglutination and hemadsorption. Synthesis of NDV-hemagglutinin-neuramidase (HN) glycoprotein was quantified by determining hemagglutination units (HAU) in whole lysates of NDV-infected cells (17). NDV-HN expressed on the cell surface was quantified by hemadsorption (HAD), as described previously (18).

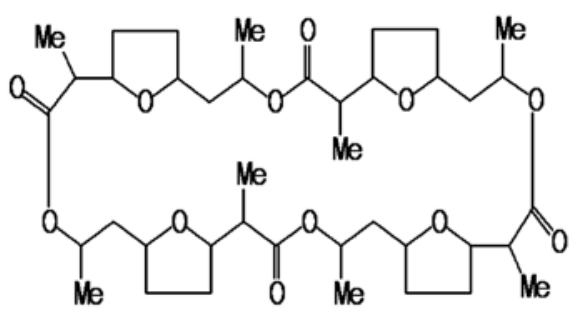

Figure 1. Structure of nonactin. Cultured broth $(201)$ was separated into supernatant and mycelium fractions by centrifugation. Mycelium $(1.43 \mathrm{~kg})$ was extracted twice with acetone and concentrated in vacuo. The aqueous acetone extract was extracted with ethyl acetate twice and concentrated in vacuo. The residue $(9.6 \mathrm{~g})$ was subjected to silica gel column chromatography (silica gel 60, 70-230 mesh, Merck Co.). The column $(40 \times 600 \mathrm{~mm})$ was developed with a solvent system of hexane:ethyl acetate. Elution was performed stepwise with a solvent ratio from 9:1 to $1: 9$ to produce six fractions, designated A-F in the order of elution. The volume of each fraction was $1000 \mathrm{ml}$. All fractions were monitored by TLC and detected under a UV lamp. Active fractions (D and F) were concentrated in vacuo. The residue was subjected to open RP18 column chromatography $(30 \times 150 \mathrm{~mm})$ with a solvent system of acetonitrile:water. Active fractions $\left(90 \% \mathrm{CH}_{3} \mathrm{CN}\right)$ were concentrated in vacuo. The residue was further purified by preparative HPLC under the following chromatographic conditions: column, YMC-Pack ODS, $\$ 250$ x $10 \mathrm{~mm}$; solvent, 95\% $\mathrm{CH}_{3} \mathrm{CN}$; flow rate, $1 \mathrm{ml} / \mathrm{min}$; detection, UV $254 \mathrm{~nm}$; retention time, $19 \mathrm{~min}$. The active peak monitored using HPLC was concentrated in vacuo to obtain a purified white powder (38 mg). The agent was identified as nonactin (12).

Fluorescence microscopy. VSV particles were purified from culture medium of VSV-infected BHK cells as described by Kelley et al (19). G protein was extracted with phosphate buffer containing Triton X-114 (17). In brief, rabbits were immunized with the $\mathrm{G}$ protein, and $\mathrm{IgG}$ was prepared from the antiserum. BHK cells were plated on glass coverslips. Overnight sparse cultures were infected with VSV. After incubation for $1 \mathrm{~h}$ at $37^{\circ} \mathrm{C}$, nonactin was added to the cultures with cycloheximide $(1 \mu \mathrm{g} / \mathrm{ml})$ prior to a further $1-\mathrm{h}$ incubation. Cells were fixed overnight in PBS containing 3\% paraformaldehyde (w/v), and washed with PBS containing $10 \mathrm{mM}$ glycine. Next, cells were permeabilized for $5 \mathrm{~min}$ in methanol or PBS containing $0.1 \%$ Triton X-100, and treated with PBS containing $0.5 \%$ bovine serum albumin to evade non-specific absorption. After exposure to anti-rabbit IgG antibody $(1 \mu \mathrm{g} / \mathrm{ml})$ for $1 \mathrm{~h}$, cells were washed 3 times with PBS. Cells were subsequently exposed to FITC-conjugated secondary antibodies $(50 \mu \mathrm{g} / \mathrm{ml})$ for $1 \mathrm{~h}$, and re-washed with PBS. Coverslips were mounted onto glass slides in 90\% glycerol with $100 \mathrm{mM}$ Tris- $\mathrm{HCl}$ (pH 7.2). Photographs were obtained using a fluorescent microscope (Zeiss, Jena, Germany).

\section{Results}

Nonactin exhibits antibacterial activities against mutant and wild-type strains of Bacillus subtilis. Antibacterial activities against mutant or wild-type Bacillus subtilis were assessed according to the zone of growth inhibition. In our experiments, nonactin displayed antibacterial activity in a dose-dependent manner, as shown in Fig. 2A. Moreover, nonactin inhibited the growth of the rec- strain more potently than that of the $\mathrm{rec}^{+}$ strain. Specifically, antibacterial activity of nonactin against the rec $^{-}$mutant was greater than that against the $\mathrm{rec}^{+}$strain (Table I). In view of the higher sensitivity of recombination- 


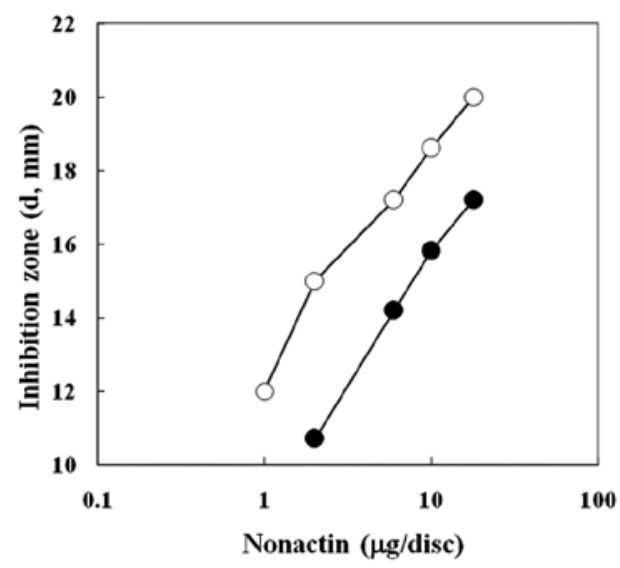

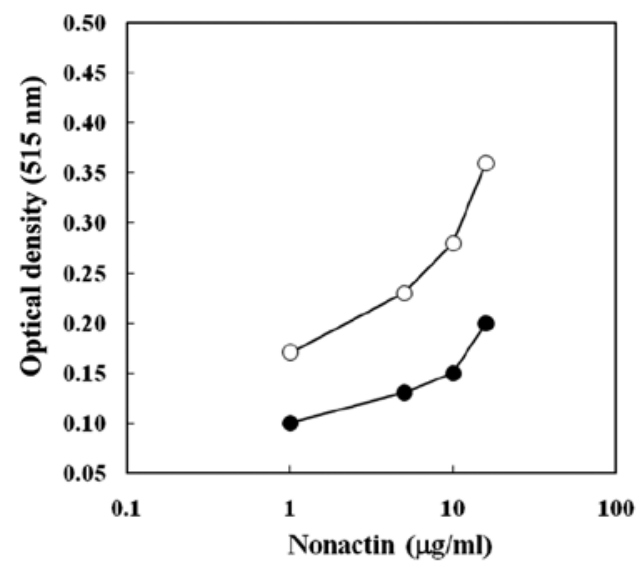

Figure 2. Antibacterial activities of nonactin against wild-type $\left(\mathrm{rec}^{+}, \bullet\right)$ and mutant $\left(\mathrm{rec}^{-}, \mathrm{O}\right)$ strains of Bacillus subtilis (A) and superoxide radical generation in B. subtilis KCTC3069 cell lysates by nonactin (B). Activity is expressed as the diameter of the growth inhibition zone surrounding paper discs on the assay plate (see Materials and methods).

Table I. Antimicrobial activities of nonactin.

\begin{tabular}{ccc}
\hline & $\begin{array}{c}\text { B. subtilis KCTC3069 } \\
\left(\mathrm{rec}^{-}\right)\end{array}$ & $\begin{array}{c}\text { B. subtilis ATCC6633 } \\
\left(\mathrm{rec}^{+}\right)\end{array}$ \\
\hline $\mathrm{IC}_{50}(\mu \mathrm{g} / \mathrm{ml})$ & 0.15 & 1.18
\end{tabular}

B. subtilis cells $\left(1 \times 10^{5}\right.$ cells $\left./ \mathrm{ml}\right)$ were incubated for 1 day with various concentrations of nonactin, and viable cells counted to determine $\mathrm{IC}_{50}$ values.

deficient mutants to antibiotics causing DNA damage, we suggest that antibiotics induce the formation of a cleavable complex of DNA and DNA gyrase (20).

Nonactin induces superoxide radical production in Bacillus subtilis. Antibacterial activities of reactive oxygen species are prevented by scavenging agents. Accordingly, the effects of dithiothreitol (DTT) on the antibacterial activities of nonactin were examined with B. subtilis KCTC3069, which is vulnerable to oxygen stress. Nonactin displayed antibacterial activity against $B$. subtilis, which was reduced upon the addition of $250 \mu \mathrm{M}$ DTT, as shown in Table II.

Next, the generation of superoxide radicals in B. subtilis cell lysates by nonactin was assessed by measuring the reduction of NBT. As shown in Fig. 2B, nonactin generated superoxide radicals in a dose-dependent manner in the presence of SOD $(130 \mu \mathrm{g} / \mathrm{ml})$. These results indicate that the antibacterial activities of nonactin are related to the generation of reactive oxygen species in cells.

Effects of nonactin on the cell surface expression of viral glycoproteins. To establish whether nonactin inhibits syncytium formation without significantly affecting glycoprotein synthesis, we examined its effects on the cell surface expression of viral glycoproteins.

BHK cells in 6-well plates were infected with NDV and incubated at $37^{\circ} \mathrm{C}$ for $12 \mathrm{~h}$ in the presence of nonactin
Table II. Effects of dithiothreitol (DTT) on the antibacterial activity of nonactin against B. subtilis KCTC3069.

\begin{tabular}{lcc}
\hline & -DTT & + DTT \\
\hline $\mathrm{IC}_{50}(\mu \mathrm{g} / \mathrm{ml})$ & 0.48 & 1.18 \\
\hline
\end{tabular}

B. subtilis $\mathrm{KCTC} 3069$ ( $1 \times 10^{5}$ cells $\left./ \mathrm{ml}\right)$ cells were incubated for 1 day with various concentrations of nonactin in the presence or absence of $250 \mu \mathrm{M}$ DTT, and viable cells were counted to determine $\mathrm{IC}_{50}$ values.

at the concentrations indicated in Fig. 4. Total and cell surface-expressed NDV-HN glycoproteins were quantified via estimation of their hemagglutination and hemadsorption activities, respectively. To quantify the total amount of NDV-HN synthesized, whole NDV-infected cultures were disrupted by brief sonication, and chicken red blood cells were added to determine hemagglutination activities in lysates. HAU was not significantly decreased at any concentration up to $5 \mu \mathrm{M}$ nonactin (Fig. 3, white). However, the binding of extracellularly added chicken red blood cells to the surfaces of intact NDV-infected cells (expressed as \% HAD) decreased depending on the nonactin concentration (Fig. 3, hatched), indicating that nonactin blocks the cell surface expression of NDV-HN glycoprotein in a dose-dependent manner. These results collectively indicate that nonactin inhibits the cell surface expression of NDV-HN, but has no significant effects on its synthesis.

Effects of nonactin on intracellular glycosylation inhibition. Cell surface expression of VSV-G was not blocked by the inhibition of protein synthesis, since intracellular accumulation was observed by immunofluorescence microscopy (Fig. 4). In the absence of methanol, which facilitates the internalization of antibodies into cells, only VSV-G expressed on the cell surface was stained (Fig. 4). The surfaces of untreated control cells were strongly stained, while those of cells treated with the inhibitors of intracellular trafficking BFA and monensin 


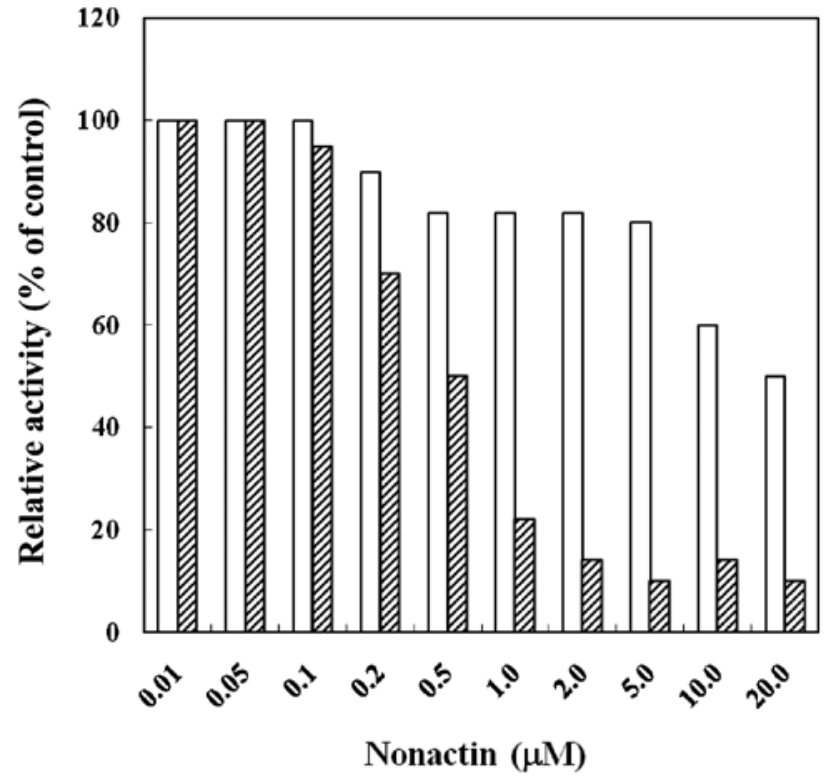

Figure 3. Blockade of the cell surface expression of NDV-HN glycoprotein by nonactin with no significant effects on its synthesis. Monolayer cultures of BHK cells in 6-well or microtiter plates were infected with NDV, and indicated concentrations of nonactin were added to the cultures hours after infection. Percentages of HAU (white) or HAD (hatched) were determined at $14 \mathrm{~h}$ of infection. NDV-HN protein synthesis was quantified by determining HAU in whole lysates of infected cultures in microtiter plates, and cell surface expression quantified by measuring the amounts of chicken red blood cells adsorbed to intact infected cells in 6-well plates. Results are expressed as a percentage of the control value.

were not. In contrast, prominent intracellular staining was evident in nonactin-treated cells (Fig. 4). In nonactin-treated cells, strong dense intracellular staining was evident, but cell surface staining was not, indicating that cell surface expression was inhibited and concomitant intracellular accumulation of VSV-G glycoprotein was achieved. Localization of the stain in nonactin-treated cells was distinct from that in cells treated with BFA or monensin, which block intracellular trafficking from the endoplasmic reticulum to the Golgi (21) or Golgi cisternae (22), respectively. The Golgi complex is fragmented by monensin, but remains localized in the perinuclear region (26). In BFA-treated cells, Golgi components are redistributed to the endoplasmic reticulum or intermediate compartments (21). Golgi staining in nonactin-treated cells was similar to that in control cells, indicating that cytoplasmically dispersed punctate immunofluorescence stains in nonactin-treated cells are caused by fragmentation of the Golgi apparatus. Further studies are required to determine the site(s) of intracellular accumulation of VSV-G. Our results collectively indicate that nonactin blocks the cell surface expression of both NDV and VSV glycoproteins.

\section{Discussion}

Glycoproteins play key roles in diverse aspects of cell physiology. These proteins are synthesized in the rough endoplasmic reticulum with concomitant glycosylation, and translocated intracellularly through the Golgi apparatus en route to their respective destinations, including the cell surface, extracellular milieu, lysosomes and other intracellular organelles (23).

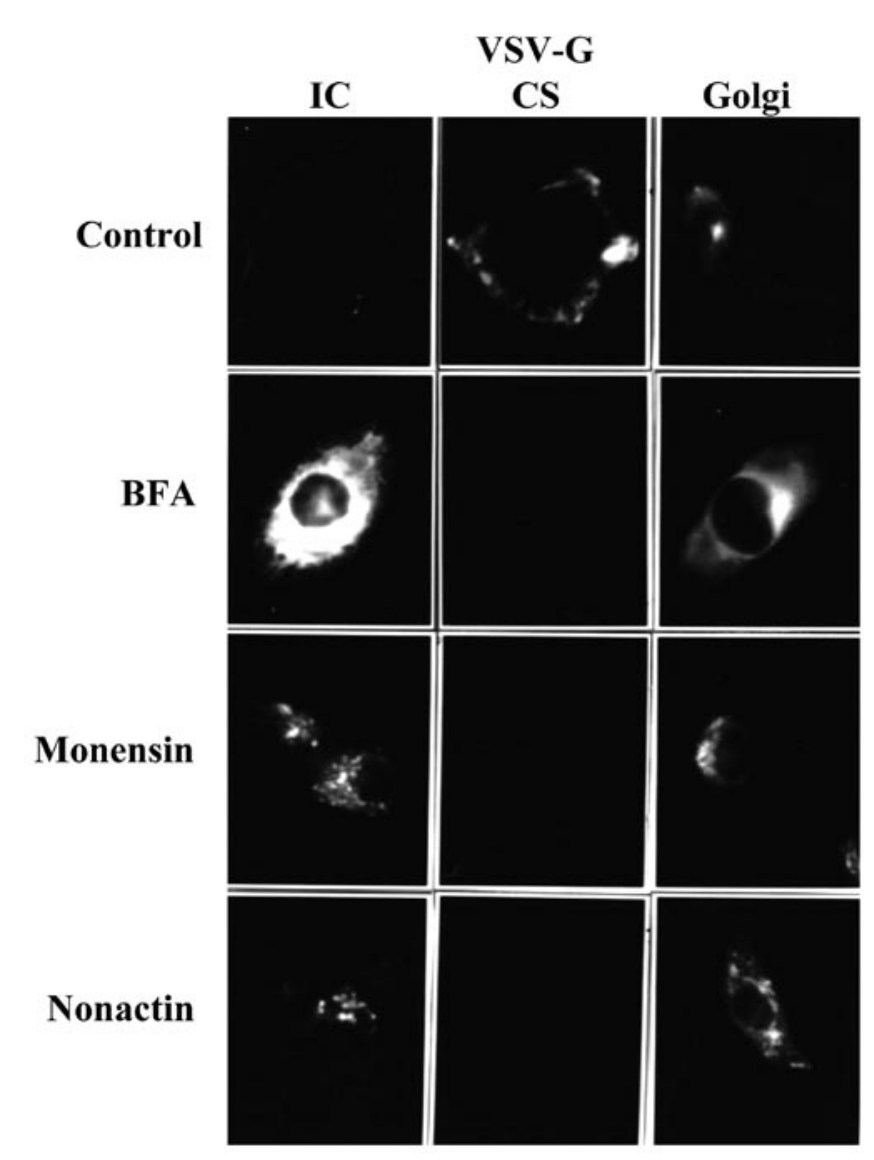

Figure 4. Immunofluorescence microscopic observation of the cell surface and intracellular region in the presence of nonactin. BHK cells on glass coverslips were infected with VSV. Brefeldin A $(2 \mu \mathrm{g} / \mathrm{ml})$, monensin $(5 \mu \mathrm{g} / \mathrm{ml})$ or nonactin $(5 \mu \mathrm{g} / \mathrm{ml})$ were respectively added at $1 \mathrm{~h}$ of infection throughout the experiment before fixation with paraformaldehyde. Infected cells were treated with cycloheximide to a concentration of $10 \mu \mathrm{g} / \mathrm{ml}$ at $8 \mathrm{~h}$ after infection, and incubated for a further $2 \mathrm{~h}$ to monitor intracellular VSV-G. Thereafter, cells were fixed and processed for immunofluorescence microscopy. Photographs were obtained using fluorescence microscopy. IC, intracellular; CS, cell surface; BFA, brefeldin A.

Trafficking is achieved by repeated cycles of budding and the fusion of transport vesicles (23). Significant efforts have been made to determine the mechanism(s) underlying glycosylation trafficking in cells, particularly with the aid of inhibitors of trafficking, which are powerful tools in these studies (21). However, limited compounds that affect intracellular trafficking processes have been identified to date.

Trafficking inhibitors, such as leucinostatin A, block the cell surface expression of viral glycoproteins without significantly affecting synthesis (24). In preliminary experiments, we observed that a trafficking inhibitor of glycoprotein produced radicals in most cells (12). Based on these findings, we hypothesize that radical-producing antibiotics partially act as trafficking inhibitors of glycoprotein in cells. We screened, isolated and purified nonactin as a radical producing agent using Bacillus subtilis (data not shown). To further establish whether nonactin inhibits the trafficking of glycoprotein, we examined its effects on the cell surface expression of viral glycoproteins in BHK cells.

Our data initially showed that nonactin inhibits syncytium formation without significantly affecting $\mathrm{HN}$ glycoprotein 
synthesis in NDV-infected BHK cells. At similar doses of nonactin, cytopathic effects and infectious virus production were suppressed in VSV-infected BHK cells. Blockade of the cell surface expression of NDV-HN and VSV-G glycoproteins by nonactin was evident, and was accompanied by intracellular accumulation of these virus glycoproteins. To our knowledge, this is the first report showing that nonactin blocks the cell surface expression of viral glycoproteins with no significant effects on their synthesis.

Additionally, blockade of the cell surface expression of viral glycoproteins was observed with leucinostatin A, another F-ATPase inhibitor structurally unrelated to nonactin (24). Therefore, further studies are necessary to determine whether the suppression of the cell surface expression of glycoproteins is a result of the inhibition of F-ATPase or of the as-yet-unidentified effects of the agent. Immunofluorescence microscopy data demonstrate that the sites of intracellular accumulation of VSV-G glycoprotein in nonactin-treated cells are distinct from those in BFA- and monensin-treated cells, indicating that nonactin has a novel mode of action in the glycoprotein trafficking pathway. We propose that nonactin can be used as a useful tool to investigate the mechanisms of the intracellular trafficking of glycoproteins.

The physiological changes of NDV and VSV in BHK cells are similar to those of the human immunodeficiency virus (HIV). HIV is the etiological vector associated with AIDS (acquired immune deficiency syndrome), ARC (AIDS-related complex) and related disorders (25). HIV infection in vitro induces syncytium formation by cell-to-cell fusion (26); hence, the potential of trafficking inhibitors as anti-HIV therapeutic agents requires further investigation.

In summary, we demonstrated that nonactin inhibits glycoprotein secretion in BHK cells, but not the synthesis of NDV glycoproteins. Our data show that nonactin suppresses the cell surface expression of VSV. We anticipate that nonactin may be effectively developed as an anti-HIV agent, dependent on in vivo analyses.

\section{Acknowledgements}

This study was supported in part by the Korea Research Foundation Grant, funded by the Korean Government (MOEHRD) (KRF-2007-412-J05502), and also by the Technology Development Program for Agriculture and Forestry, Ministry of Food, Agriculture, Forestry and Fisheries, Republic of Korea.

\section{References}

1. Wattenberg BG: Glycolipid and glycoprotein transport through the Golgi complex are similar biochemically and kinetically. Reconstitution of glycolipid transport in a cell free system. J Cell Biol 111: 421-428, 1990.

2. Bos CR, Shank SL and Snider MD: Role of clathrin-coated vesicles in glycoprotein transport from the cell surface to the Golgi complex. J Biol Chem 270: 665-671, 1995.

3. Muñiz M and Riezman H: Intracellular transport of GPI-anchored proteins. EMBO J 19: 10-15, 2000.
4. Hunziker W and Geuze HJ: Intracellular trafficking of lysosomal membrane proteins. Bioessays 18: 379-389, 1996.

5. Spearman P: Cellular cofactors involved in HIV assembly and budding. Curr Opin HIV AIDS 1: 200-207, 2006.

6. Olkkonen VM and Ikonen E: When intracellular logistics fails - genetic defects in membrane trafficking. J Cell Sci 119: 5031-5045, 2006.

7. Happe S and Weidman P: Cell-free transport to distinct Golgi cisternae is compartment specific and ARF independent. J Cell Biol 140: 511-523, 1998

8. Mironov AA, Colanzi A, Polishchuk RS, Beznoussenko GV, Mironov AA Jr, Fusella A, Di Tullio G, Silletta MG, Corda D, De Matteis MA and Luini A: Dicumarol, an inhibitor of ADP-ribosylation of CtBP3/BARS, fragments Golgi noncompact tubular zones and inhibits intra-golgi transport. Eur J Cell Biol 83: 263-279, 2004

9. Lad VJ and Gupta AK: Inhibition of Japanese encephalitis virus maturation and transport in PS cells to cell surface by brefeldin A. Acta Virol 46: 187-190, 2002.

10. Thomas G: Furin at the cutting edge: from protein traffic to embryogenesis and disease. Nat Rev Mol Cell Biol 3: 753-766, 2002.

11. Sheetz MP, Pfister KK, Bulinski JC and Cotman CW: Mechanisms of trafficking in axons and dendrites: implications for development and neurodegeneration. Prog Neurobiol 55: 577-594, 1998.

12. Lee JM, Lee DS, Lee SH, Hong SD and Kim JG: Antibacterial activities of nanactin from Streptomyces viridochromogenes JM-4151. J Life Sci 10: 45-47, 2000.

13. Barry AL, Creitz L and Packer PP: Feasibility study of disk diffusion susceptibility tests with Mueller-Hinton broth solidified with Gelrite, an agar substitute. J Clin Microbiol 21: 409-414, 1985.

14. Smaill F: Antibiotic susceptibility and resistance testing: an overview. Can J Gastroenterol 14: 871-875, 2000.

15. Baker JR, Zyzak DV, Thorpe SR and Baynes JW: Mechanism of fructosamine assay: evidence against role of superoxide as intermediate in nitroblue tetrazolium reduction. Clin Chem 39: 2460-2465, 1993.

16. Lee DS, Lee SH, Noh JG and Hong SD: Antibacterial activities of cryptotanshinone and dihydrotanshinone I from a medicinal herb, Salvia miltiorrhiza, Bunge. Biosci Biotechnol Biochem 63: 2236-2239, 1999.

17. Muroi M, Takasu A, Yamasaki M and Takatsuki A: Folimycin (concanamycin A), an inhibitor of V-type $\mathrm{H}(+)$-ATPase, blocks cell-surface expression of virus-envelope glycoproteins. Biochem Biophys Res Commun 193: 999-1005, 1993.

18. Muroi M, Shiragami N and Takatsuki A: Destruxin, a specific and readily reversible inhibitor of vacuolar-type $\mathrm{H}(+)$-translocating ATPase. Biochem Biophys Res Commun 205: 1358-1365, 1994.

19. Kisch AL, Kelley RO and Eberle BJ: Differential enhancement of R-type virus particles in polyoma-transformed BHK-21 cells by dimethyl sulfoxide. J Natl Cancer Inst 49: 911-914, 1972.

20. Osburne MS, Maiese WM and Greenstein M: An assay for the detection of bacterial DNA gyrase inhibitors. J Antibiot 46: 1764-1766, 1993.

21. Nakamura M, Kono Y and Takatsuki A: Mepanipyrim, a novel inhibitor of pharmacologically induced Golgi dispersion. Biosci Biotechnol Biochem 67: 139-150, 2003.

22. Zizi M, Fisher RS and Grillo FG: Formation of cation channels in planar lipid bilayers by brefeldin A. J Biol Chem 266: 18443-18445, 1991.

23. Hiebsch RR and Wattenberg BW: Vesicle fusion in protein transport through the Golgi in vitro does not involve longlived prefusion intermediates. A reassessment of the kinetics of transport as measured by glycosylation. Biochemistry 31 : 6111-6118, 1992.

24. Muroi M, Suehara K, Wakusawa H, Suzuki K, Sato T, Nishimura T, Otake N and Takatsuki A: Novel blockade of cell surface expression of virus glycoproteins by leucinostatin A. J Antibiot 49: 1119-1126, 1996.

25. Quinn TC: HIV epidemiology and the effects of antiviral therapy on long-term consequences. AIDS 22 (Suppl 3): 7-12, 2008. 